\title{
Commentary: Living-donor lobar lung transplantation-An elegant solution to organ shortage
}

\author{
Usman Ahmad, MD, and Kenneth R. McCurry, MD
}

\author{
From the Department of Cardiothoracic Surgery, Heart and Vascular Institute, Cleveland Clinic, Cleveland, Ohio. \\ Disclosures: Authors have nothing to disclose with regard to commercial support. \\ Received for publication Sept 11, 2019; revisions received Sept 11, 2019; accepted for publication Sept 11, 2019; \\ available ahead of print Oct 25, 2019. \\ Address for reprints: Usman Ahmad, MD, Department of Cardiothoracic Surgery, Heart and Vascular Institute, \\ Cleveland Clinic, Cleveland, OH 44195 (E-mail: ahmadu@ccf.org). \\ J Thorac Cardiovasc Surg 2020;159:e91-2 \\ $0022-5223 / \$ 36.00$ \\ Copyright (C) 2019 by The American Association for Thoracic Surgery \\ https://doi.org/10.1016/j.jtcvs.2019.09.012
}

In the era before the Lung Allocation Score, organ shortages for critically ill patients led to development and popularization of living-donor lobar transplantation in the United States. ${ }^{1,2}$ Since the implementation of Lung Allocation Score, high-priority patients have had shorter times on the wait list, and the need for a morbid donor operation (ie, lobectomy) is thus decreased. ${ }^{3}$ In Japan, however, where the organ allocation and procurement systems are constrained, use of living lobar grafts has flourished. ${ }^{4}$ Date's group have developed and demonstrated excellent technical results and shown that in well-selected patients living donor lobar transplantation can lead to excellent pulmonary function.

In the report by Nakajima and colleagues ${ }^{5}$ in this issue of the Journal, Date's group have compared the posttransplant pulmonary function between patients who underwent bilateral living donor lobar transplantation and those who received cadaveric full lung allografts. The results of the study show some very interesting findings.

The lobar grafts were sized such that the graft forced vital capacity (FVC) was more than $45 \%$ to $50 \%$ of the recipient predicted FVC. For cadaveric allografts, the predicted vital capacity for height was $100 \% \pm 30 \%$ of the recipient vital capacity for height. This sizing strategy resulted in the lobar grafts measuring only $65 \% \pm 18 \%$ of recipient predicted, whereas the cadaveric grafts were measured at $98 \% \pm 15 \%$ of recipient predicted vital capacity. Despite some undersizing of the lobar grafts, the measured forced expiratory volume in 1 second, FVC and vital capacity followed similar trends and measured values in the 2 groups. At the 3-year time point, statistically higher forced expiratory volume in 1 second and FVC were noted in the cadaveric group.

These findings are quite intriguing, because the positive correlation between amount of transplanted parenchyma and posttransplant forced expiratory volume in 1 second is well known, as seen in comparisons between single- and double-lung transplantation. ${ }^{6}$ Nakajima and colleagues ${ }^{5}$ propose that the relatively lower spirometric values in the cadaveric group could be due to a smaller function.

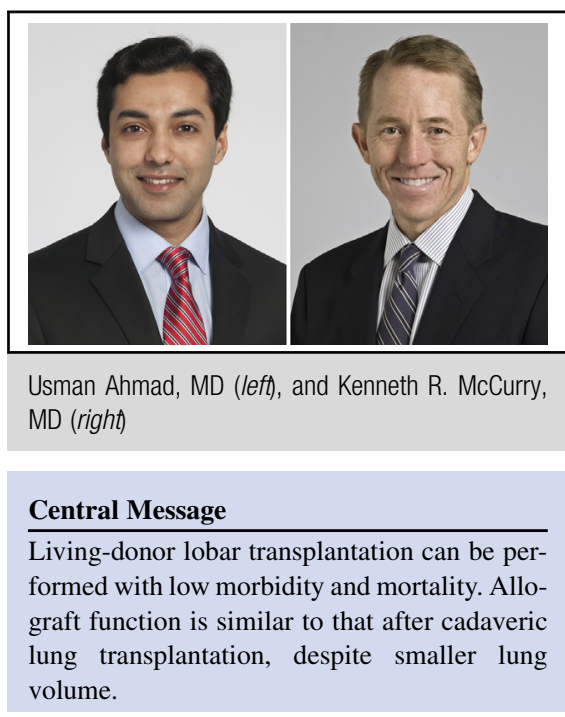

See Article page e87.

pleural space secondary to restrictive disease. In their cohort, however, the vast majority of patients with interstitial disease underwent lobar transplantation, which argues against this hypothesis. It is important to note that 9 of 38 patients in the cadaveric group required anatomic downsizing of the allograft, which may have somewhat equilibrated the amount of transplanted parenchyma relative to the lobar group. More importantly, this difference may highlight the importance of unrecognized factors related to cadaveric procurement and longer ischemic time in the cadaveric group (3.5 times longer). Biologic mechanisms related to ischemia-reperfusion may have broader effects on immediate and long-term allograft

The other remarkable finding is that allograft function continued to improve until the 2-year time point in the lobar group and the 3-year time point in the cadaveric group. Most reports show plateauing of pulmonary function close to the 1-year posttransplant time point. ${ }^{6,7}$ This may reflect differences in posttransplant rehabilitation and possibly medical management. Further investigation into the underlying effect is important for the pulmonary transplantation community.

Overall, Nakajima and colleagues ${ }^{5}$ are to be congratulated on achieving excellent results in this difficult patient population. The low 30-day and hospital mortalities are a testament to excellent surgical conduct and meticulous 
postoperative care. Although their need to perform lobar transplants is dictated by organ unavailability, their work has helped move the field of lobar transplant forward.

\section{References}

1. Starnes VA, Barr ML, Cohen RG. Lobar transplantation. indications, technique, and outcome. J Thorac Cardiovasc Surg. 1994;108:403-10; discussion 410-1.

2. Starnes VA, Barr ML, Cohen RG, Hagen JA, Wells WJ, Horn MV, et al. Living-donor lobar lung transplantation experience: intermediate results. J Thorac Cardiovasc Surg. 1996;112:1284-90; discussion 1290-1.

3. Valapour M, Lehr CJ, Skeans MA, Smith JM, Carrico R, Uccellini K, et al. OPTN/ SRTR 2016 annual data report: Lung. Am J Transplant. 2018;18(Suppl 1):363-433.
4. Date H, Aoyama A, Hijiya K, Motoyama H, Handa T, Kinoshita H, et al. Outcomes of various transplant procedures (single, sparing, inverted) in living-donor lobar lung transplantation. J Thorac Cardiovasc Surg. 2017;153: 479-86.

5. Nakajima D, Chen-Yoshikawa TF, Ohsumi A, Date H. Living-donor lobar lung transplants provide comparable pulmonary function to cadaveric lung transplants. J Thorac Cardiovasc Surg. 2020;159:e87-90.

6. Mason DP, Rajeswaran J, Murthy SC, McNeill AM, Budev MM, Mehta AC, et al. Spirometry after transplantation: how much better are two lungs than one? Ann Thorac Surg. 2008;85:1193-201.e1-2.

7. Azar M, Krishnan S, Stump TE, Gutteridge D, Roe DW, Hage C. Peak post-transplant lung function in bilateral lung transplant recipients using a prediction model based on donor and recipient demographic characteristics. Respir Med. 2019;155:29-35. 